\title{
BASES EPISTEMOLÓGICAS DA ANTIPSIQUIATRIA: A INFLUÊNCIA DO EXISTENCIALISMO DE SARTRE
}

\author{
Epistemological Axes of Anti-Psychiatry: The Influence of Sartre's Existencialism \\ Bases Epistemológicas de la Antipsiquiatría: La Influéncia del Existencialismo de Sartre
}

BIANCA SPOHR

DANIEla Ribeiro SCHNEIDER

\begin{abstract}
Resumo: O movimento antipsiquiátrico, iniciado por volta dos anos 1950, especialmente na Europa e Estados Unidos, foi responsável pelo amplo questionamento ao modelo psiquiátrico de compreensão e atenção à loucura. Da crítica ao conceito de "doença mental" até os questionamentos dos modelos de tratamento centrados nos hospitais psiquiátricos, por serem considerados produtores de violência e exclusão, além de não possibilitarem a efetiva recuperação e a reinserção do paciente na sociedade, o movimento foi fundamental na criação de novos modelos de atenção em saúde mental. O presente trabalho discute a influência do existencialismo de Sartre na constituição das bases epistemológicas que produziram a antipsiquiatria, a fim de refletir sobre a problemática da loucura na contemporaneidade. A filosofia sartriana - sustentada no conceito de liberdade enquanto condição humana por excelência - forneceu subsídios para a compreensão da psicopatologia como um processo que ocorre nas relações do sujeito em seu contexto sócio-histórico, com ênfase nas relações familiares; opondo-se à noção de entidade mórbida, de cunho organicista, que imperava na tese psiquiátrica. Retomar as raízes epistemológicas do movimento antipsiquiátrico é um importante meio para se realizar a indispensável discussão em torno das contradições teórico-práticas atuais na área da saúde mental.
\end{abstract}

Palavras-chave: Antipsiquiatria; Sartre; História da Loucura; Psicologia Existencialista; Epistemologia.

\begin{abstract}
The anti-psychiatric movement, which started around the 1950's, was responsible for the extensive questioning of the psychiatric model for understanding and treating madness, especially in Europe and the United States. The movement had a central role in the creation of new models for dealing with mental health, as it criticized the concept of "mental disease", questioning the treatment models based on psychiatric hospitals, which were considered to produce violence and exclusion, besides not providing effective patient's recovery and re-entry in society. This paper discusses the influence Sartre's existentialism currently has on the issue of madness. The Sartrian philosophy - which is based on the concept of freedom as a human condition par excellence - has supported the understanding of psychopathology as a process that occurs within the relations of the subject in his/her socio-historical context, specially in the family relations; as opposed to the notion of morbid entity, characterized by its organicity, which guide the psychiatric thesis. Reanalyzing the epistemological roots of anti-psychiatric movement is an important mean of stimulating the essential discussion regarding the current contradictions between theory and practice in the area of mental health.
\end{abstract}

Keywords: Anti-psychiatry; Sartre; History of Madness; Existentialistic Psychology; Epistemology.

Resumen: El movimiento antipsiquiátrico, que empezó alrededor del año 1950, especialmente en Europa y Estados Unidos, fue responsable del amplio cuestionamiento del modelo psiquiátrico de compreensión y atención a la locura. Desde la crítica al concepto de "enfermedad mental", hasta los planteamientos de las modalidades de tratamiento centrados en los hospitales psiquiátricos; al estar considerados productos de violencia y exclusión; además de no posibilitar la efectiva recuperación y la reinserción del paciente en la sociedad, el movimiento fue fundamental en la creación de nuevos modelos de atención en salud mental. El presente trabajo discute la influencia del existencialismo de Sartre en la formación de las bases epistemológicas que produjeron la antipsiquiatría, con la finalidad de reflexionar sobre el problema de la locura en la época contemporanea. La filosofía sartriana - que se sostiene en el concepto de libertad ya que es la condición humana por excelencia - ofreció subsídios para la comprensión de la psicopatología como un proceso que ocurre en las relaciones del sujeto en su contexto socio-histórico, con énfasis en las relaciones familiares; oponiéndose a la idea de entidad mórbida, de cuño organicista, que imperaba en la tesis psiquiátrica. Retomar las raices epistemológicas del movimiento antipsiquiátrico es un importante médio para que ocurra la indispensable discusión alrededor de las contradiciones teórico-prácticas actuales en el área de la salud mental.

Palabras-clave: Antipsiquiatría; Sartre; Historia de la Locura; Psicología Existencialista; Epistemologia. 


\section{Introdução}

Para compreender a situação da loucura ou do sofrimento psíquico em tempos contemporâneos é importante estudar a história de seus conceitos, abordando-a em termos dialéticos, ou seja, compreender como se instalaram as forças contraditórias que constituíram seu saber ao longo dos tempos.

Desta forma, tem-se como marco inicial da modernidade a constituição da antítese à explicação medieval da loucura como possessão demoníaca, que tornou-se a tese hegemônica da contemporaneidade até nossos dias atuais: a perspectiva médico-psiquiátrica, sustentada no conceito de "doença mental". Este conceito passou a ser o pilar de sustentação do edifício psiquiátrico, com suas perspectivas epistemológicas predominantes: os chamados "transtornos mentais" têm determinação orgânica, de base hereditária e são tomados numa perspectiva individual, tendo, portanto, desdobramentos para o funcionamento mental e comportamental do indivíduo. Não há relação de determinação com as relações sociais, embora se considere os prejuízos causados pela loucura na ordem sócio-familiar. Tais concepções desdobram-se em práticas de internação e em diversas terapêuticas, que vão desde o acorrentamento, passando pela aplicação de banhos quentes e frios, pelo tratamento moral, pela lobotomia, pelos choques insulínicos e elétricos, até a vasta e indiscriminada administração de psicofármacos, a partir dos anos 1950.

Exatamente por estes anos surgiram críticas contundentes ao modelo psiquiátrico. A sua antítese começou pelo questionamento da noção de "doença mental” e seus pressupostos, considerada por Szasz (1979) como um mito. Para este autor, sua função seria a de "dourar a amarga pílula” dos conflitos sociais ao transformar os problemas de relacionamento social em uma questão individual, da ordem de disfunções neuroquímicas ou mentais. Logo o questionamento ampliou-se para as formas de tratamento, criticando a desumanização de suas práticas e a falta de efetividade das ações psiquiátricas ditas terapêuticas. Estas acabaram por retirar a voz e a cidadania do louco, isolando-o de suas relações sóciocomunitárias.

Surgiram, assim, iniciativas cujo objetivo era o de reformar o modelo psiquiátrico, como foram os casos das Comunidades Terapêuticas, na Inglaterra, e da Psicoterapia Institucional, na França, nos anos 1940-50. Estas modalidades propuseram mudanças dentro da própria instituição asilar. Já a Psiquiatria de Setor, na França, e a Psiquiatria Preventiva, nos Estados Unidos, propuseram serviços terapêuticos alternativos ao manicômio, nos anos 60 e 70 (Amarante, 2007).

Por outro lado, constituíram-se iniciativas cujo objetivo era promover a ruptura com o modelo psiquiátrico manicomial. Este é o caso do movimento antipsiquiátrico, iniciado na Inglaterra, nos anos 50 e 60, atingindo a França e Itália, os EUA e outros países. Também fundamental nesta perspectiva de ruptura foi o movimento de transformação prática, chamado de Psiquiatria Democrática, que produziu mudanças significativas nas formas de atenção à loucura, desconstruindo a lógica manicomial e promovendo a desinstitucionalização da loucura. Começou em Trieste, na Itália, nos anos 70, com Franco Basaglia, e espalhou-se pelo mundo (Amarante, 2007). Esses movimentos têm mútuas influências, formando o cenário do que vamos denominar de antítese.

Desde então, no cenário da saúde, a tese e antítese vêm em constante embate teórico, prático e político.

O desenvolvimento teórico e prático da psiquiatria levou-a a consolidar-se, pouco a pouco, como um importante instrumento de controle social, já que prestava o serviço de "amparo" àquele sujeito inadaptado à vida social burguesa. Realizava, com isso, uma ação de higienização social. Cabia-lhe a tarefa "de agir sobre o 'foco da desordem' (...). Sua ação específica era a de recolher as sobras humanas do modo de produção capitalista, trancálos nos hospícios e se possível, recuperá-los, ajustado-os ao trabalho e ao novo modo de produção" (Santos, 1994, p. 32). Tornou-se, assim, o agente normalizador, a garantia da ordem sócio-familiar, por meio da educação higiênica (Costa, 1983).

Com Pinel, no século XIX, houve a introdução de uma visão de cunho mais psicológica e a proposta de um tratamento moral: a psiquiatria devia realizar a correção dos hábitos, através da correção das idéias, buscando modificar o comportamento do sujeito, numa intervenção que já se dava na direção do que seria uma análise do comportamento, segundo Pessotti (2006). Com isso, cumpria a função de controle social acima descrito.

No entanto, a maioria dos psiquiatras não corroborava com estas concepções que levavam em consideração o papel ativo da pessoa no enlouquecimento, esforçando-se por retomar a lógica organicista. Desta forma, " $a$ o tratamento moral impôs-se triunfante o tratamento físico, destinado a provocar efeitos sobre o funcionamento do cérebro" (Pessotti, 2006, p. 113).

Gradativamente, portanto, as práticas psiquiátricas foram se tornando mais e mais coercitivas e violentas, ficando evidente - a despeito de sua dita "modernização" e "cientificização"- sua visão determinista que se desdobrava, na prática, na incapacidade de reintegrar os "doentes mentais" à sociedade e ao mundo do trabalho. Deste modo, a psiquiatria não tardou a ser alvo de severas críticas e tais questionamentos levaram "tanto à problematização crescente dos seus fundamentos epistemológicos, teóricos, metodológicos e institucionais, quanto ao desvelamento de sua função social e política: violência, controle social e segregação" (Leone, 2000, p. 123).

Sendo assim, o movimento antipsiquiátrico, surgido na Europa, especialmente na Inglaterra, França e Itália, mas também nos Estados Unidos, representou, de acordo 
com Delacampagne (2004), uma clara oposição a todo o aparato conceitual e operacional da chamada "medicina mental", tendo como ponto de partida os conceitos de "normal" e "patológico". A crítica mais profunda à psiquiatria, como afirma Amarante (2007, p. 52), "refere-se ao seu marco teórico-conceitual que, ao adotar o mesmo modelo de conhecimento das ciências naturais, produzira um enorme equívoco metodológico".

Estes movimentos críticos à psiquiatria e a violência simbólica intrínseca ao seu modelo acompanharam as lutas por liberdade e melhoria na qualidade de vida das pessoas, que varreram a segunda metade do século XX em todo o mundo, em vários setores da vida humana. Foram influenciados por filósofos que realizavam questionamentos mais amplos no campo teórico-metodológico, tais como: Husserl, Heidegger, Jean Paul Sartre, Michel Foucault, Deleuze e Guatarri, entre outros.

Procurando contribuir para a discussão realizada acima, este artigo tem por objetivo compreender em que medida a filosofia existencialista de Jean-Paul Sartre impulsionou os movimentos de ruptura com a tese hegemônica, fornecendo subsídios teórico-metodológicos para a consolidação do Movimento Antipsiquiátrico e da Psiquiatria Democrática.

\section{A Importância da Fenomenologia para 0 Questionamento ao Modelo Psiquiátrico}

Ao final do século XIX, de acordo com Pessotti (1994), floresceu a necessidade de uma nova atitude do médico frente à questão da loucura: a atitude clínica, ou seja, a importância de observar o comportamento do paciente alienado. Assim, no início do novo século, a psiquiatria seguiu pressionada e exigida a ir além da mera descrição dos sintomas. Era preciso, como afirmou Jaspers, psiquiatra fenomenológico, autor que veremos detalhadamente abaixo, adotar uma postura compreensiva frente ao adoecer psíquico em detrimento de uma busca por causalidades: Eis o terreno em que nasceram as críticas à lógica determinista que imperava no seio da psiquiatria. Era crucial compreender que o adoecer psíquico ocorria a partir do existir humano, ou seja, como resultado de um processo de construção de uma personalidade no meio do mundo e em meio às relações com os outros, em oposição à noção de "doença mental" - sustentada em perspectiva individualizante, mecanicista e de base neurofisiológica - que não só inviabilizava a compreensão do fenômeno "adoecimento psíquico" na sua totalidade, como também impedia o próprio sujeito de emancipar-se do peso de seu "rótulo", já que ele era entendido como oriundo de problemas internos (psicológicos e/ou cerebrais).

A Fenomenologia fornecerá substratos filosóficos para romper com esta lógica determinista. Filosofia surgida no final do século XIX, inaugurada com Edmund
Husserl (1859-1938), buscou se opor ao pensamento especulativo da filosofia metafísica dominante até então, ao mesmo tempo em que criticava o raciocínio das ciências positivas predominantes naquele cenário histórico (Dartigues, 1992). O primeiro produzia conceitos abstratos, despregados da realidade; o segundo, especialmente quando se tratava das ciências do homem, tinha uma perspectiva naturalizante, transformando processos sociais e psicológicos em elementos naturais. $\mathrm{O}$ fenomenólogo criticava também as ciências por se reduzirem a um mero empirismo, ou seja, a uma descrição de fatos sucessivos sem o questionamento da essência desses fatos.

Portanto, era necessário constituir uma "filosofia de rigor", que fornecesse novos fundamentos para as ciências. Para realizar essa nova perspectiva filosófica, Husserl propõe um método de investigação, que deve ter como ponto de partida a "volta às coisas mesmas", ou seja, a filosofia deve estabelecer seus conhecimentos e verdades sustentada na descrição da realidade circundante, como é apreendida pelo homem, enquanto ser consciente. As coisas ou os variados aspectos da realidade humana e natural na forma como aparecem para a consciência constituem o que se define por fenômeno (Schneider, 2002).

Pautado nessa concepção, Husserl proporá uma nova noção de consciência, não mais como uma estrutura fechada, mas como abertura para os fenômenos, ou seja, como intencionalidade. Isto quer dizer que só há consciência na medida em que ela é "consciência de alguma coisa”, ou seja, ela é sempre relação a algum objeto e nunca um ser sustentado em-si mesmo. Essas postulações estão na base da compreensão do homem como serno-mundo, contribuição fundamental na compreensão do sujeito humano como um ser em relação, em franca ruptura com a lógica individualizante que até então imperava (Schneider, 2002).

A Psiquiatria Fenomenológica constituiu-se a partir do momento em que alguns profissionais da medicina passaram a se interessar pelas concepções defendidas por Husserl e, também, por Heidegger, pois estas filosofias forneciam elementos para se compreender o existir humano, portanto, as condições para a constituição do sujeito, e daí, para a ocorrência das dificuldades psicológicas e das psicopatologias. Os psiquiatras fenomenológicos mais conhecidos foram Jaspers, Binswanger, Minkowski, Boss, entre outros (Pessotti, 2006). Influenciado por esta abordagem, também teve contribuição fundamental neste processo crítico a filosofia existencialista de Sartre, que, em conjunto com a fenomenologia, forneceram bases epistemológicas à reformulação teórica e metodológica do modelo psiquiátrico, com claros impactos no movimento antipsiquiátrico.

Neste artigo vamos nos dedicar ao estudo das contribuições de Jaspers e Sartre. 


\section{A Influência de Jaspers na Crítica Sartriana à Psiquiatria}

Nos anos 1920, quando Sartre ainda era estudante na École Normale Superière, colaborou na tradução para o francês do livro Psicopatologia Geral, de Karl Jaspers, que muito o influenciou. Esse foi seu primeiro contato com a fenomenologia, perspectiva que marcou sua trajetória filosófica e seu primeiro estudo sistemático de psicopatologia. A partir da fenomenologia, pode delinear uma visão crítica e contrária às concepções clássicas em psiquiatria.

A obra do psiquiatra alemão, de 1913, foi determinante para os estudos da área e tornou-se referência obrigatória para pesquisadores e psiquiatras clínicos. Mas em que consistiu a importância dessa obra? Primeiro, é preciso entender que Jaspers buscou responder aos anseios e questionamentos da psiquiatria de sua época. Essa disciplina, no início do século XX, procurava firmar sua credibilidade no meio às ciências médicas. Dividida entre os modelos organicista e psicológico, oscilava em indefinições em torno de seu objeto e em imprecisões diagnósticas e terapêuticas. A psicanálise começava a lhe exigir uma postura que fosse além da mera descrição de sintomas e fornecesse uma interpretação do adoecer psíquico. A psiquiatria, porém, oferecia um horizonte interpretativo que não conseguia escapar da lógica determinista e mecanicista, há muito questionada.

Jaspers, influenciado por Wilhelm Dilthey, que estabeleceu a distinção entre ciências da natureza (que usam o método explicativo) e ciências do espírito (que usam do método compreensivo), delineou uma nova perspectiva para a psicopatologia ao romper com a lógica analítica, embasada na noção de causalidade, predominante no modelo neurofisiológico e organicista da psiquiatria de então. Propôs novos parâmetros para essa disciplina a partir da noção de compreensão e sua lógica sintética, sustentados na fenomenologia de Husserl. Realizou, assim, uma revisão dos princípios da psicopatologia clássica, abrindo-lhe novos horizontes. Conforme explicou: "a fim de evitar confusões, empregaremos sempre a expressão 'compreender' para indicar a intuição do psíquico adquirida por dentro. O conhecimento das conexões causais objetivas, que sempre são vistas de fora, nunca chamaremos de compreensão, mas sempre de explicação" (Jaspers, 1979, p. 42).

O psiquiatra enfatizou, ao descrever os conceitos fundamentais de sua psicopatologia, a necessidade de uma perspectiva de "totalidade" para se compreender os fenômenos psicológicos. Neste aspecto foi influenciado pelos teóricos da Psicologia da Gestalt, que se colocavam em oposição ao atomismo predominante na ciência da época, também influenciados pela fenomenologia. Jaspers criticou, também, a lógica da "infinidade” ou, como Sartre definirá mais tarde, "o recurso ao infinito", típico da ciência empírica, como é o caso da psiquiatria. Exemplificou:

se, ao escrever o histórico de um paciente, se proceder segundo o princípio de não emitir juízo, mas de descrever tudo possível, de anotar tudo que ele disser, de recolher tudo que possa saber, caio facilmente sobretudo quando guiado por uma conscienciosidade e cuidado formal - na exposição de histórias sem fim (Jaspers, 1979, p. 45).

Sustentado na fenomenologia, destacou os fatos objetivos significativos em relação ao psicológico: a) a psique humana exprime-se no corpo; b) O homem vive em seu mundo; c) O homem objetifica-se na fala, no trabalho, nas idéias. Para compreender esses fatos objetivos seria preciso buscar as conexões compreensivas da vida psíquica, com destaque para a noção de "situação" e de "realidade", além do reconhecimento da "vida simbólica".

Essa compreensão deveria ser feita a partir da realização de uma "biografia" do paciente, considerada etapa fundamental para a inteligibilidade do caso, somada à sua história clínica. Afirmou que a vida psíquica é um "todo" com forma temporal. A vida humana é uma abertura para o futuro, portanto ela não é fechada sobre si mesma; é sempre uma biografia incompleta e aberta, porque à espera das realizações futuras. Além disso, a biografia leva a uma perspectiva histórica mais ampla, que vê o homem inserido em um contexto abrangente: através da história pessoal deve-se chegar na história dos povos.

Ao realizar a discussão dos quadros nosológicos, insistiu que a questão essencial que o clínico deveria se propor era: como é que todos os aspectos mórbidos e sadios se juntam em um caso individual? Os psiquiatras buscavam a resposta em uma "unidade nosológica" em que se pudesse acomodar os diferentes tipos de psicoses, projeto fracassado até então. O objetivo desse modelo de psiquiatria seria impossível de se alcançar, visto reduzirse a uma mera descrição de sintomas e nosologias, como podemos verificar hodiernamente no DSM IV e, com isso, cair na infinitude.

Argumentou, também, que a questão psicopatológica fundamental estaria relacionada ao desenvolvimento da personalidade, horizonte em que ela deveria ser compreendida. Dessa forma, compreende que a doença realiza-se no núcleo da existência. Assim, seria preciso compreender o homem todo em sua enfermidade, ou seja, a doença enquanto uma dimensão da vida deste homem (Jaspers, 1979).

Acrescentou, ainda, que além da psicopatologia se deparar com o homem enquanto "ente natural”, o encontra, também, como "ente cultural”. Dessa forma, se o homem tem, de um lado, predisposições somáticas - a "herança” é, de outro lado, pela "tradição", que ele adquire sua vida psíquica real, advinda pelo perimundo social. 
O psiquiatra deverá, assim, sempre realizar junto com a anamnese clínica tradicional uma "anamnese social" de seus pacientes, descrevendo claramente as diferentes condições ambientais de onde provêm, para dar substrato para a compreensão de sua doença. Na ótica dessa relação indivíduo/sociedade, afirmou ser importante para o psiquiatra buscar conhecer a significação da "situação sociológica da doença”, ou seja, a maneira como a cultura e o ambiente criam e interferem nas enfermidades. Citou o exemplo do ambiente civilizado moderno, cheio de estimulantes e drogas que influenciam a vida das pessoas. Tais concepções estão na base dos futuros questionamentos e proposições da antipsiquiatria.

Dessa forma, pode-se dizer que Jaspers rompeu com a psicopatologia clássica e até com a psicopatologia psicanalítica, por não buscar entender o "homem" a partir da "doença", mas, ao contrário, a "doença" a partir do "existir humano". São justamente os homens que têm a abertura do existir, que são um "vir-a-ser”, e, por isso mesmo, devem conquistar sua realização pessoal, por meio da qual transcendem seus instintos e sua condição animal. É somente nesse processo que o adoecer psíquico é possível, posto que é um "acidente" no percurso humano. Jaspers derrubou, assim, a lógica determinista do adoecer, seja ele fruto de mecanismos neurofisiológicos ou de distúrbios mentais que dominam o homem sem ele se dar conta. Em síntese, a patologia é entendida como uma produção humana realizada a partir de seu mundo e de suas relações sociais e sociológicas.

Pode-se compreender agora o quanto as concepções de Jaspers influenciaram o existencialista. A psicopatologia, a partir das concepções sartrianas, deve ser pensada dentro dos mesmos delineamentos de Jaspers, ainda que de forma crítica, conforme descreveu Simone em suas memórias:

à psicologia analítica e empoeirada que ensinavam na Sorbonne, ele (Sartre) desejava opor uma compreensão concreta, logo sintética dos indivíduos. Essa noção, ele tinha encontrado em Jaspers, cujo tratado de psicopatologia, escrito em 1913, fora traduzido em 1927; corrigira as provas do texto francês com Nizan. Jaspers opunha à explicação causal, utilizada nas ciências, outro tipo de pensamento que não se assenta em nenhum princípio universal, mas que apreende relações singulares, mediante intuições, mais afetivas do que racionais e de irrecusável evidência; ele a definia e justificava a partir da fenomenologia. Sartre ignorava tudo dessa filosofia, mas nem por isso deixara de reter a idéia de compreensão e de tentar aplicá-la (Beauvoir, 1960, p. 52-3).

Muitos dos temas centrais discutidos por Sartre forma primeiramente trabalhados por Jaspers, tais como: a) a crítica à infinitude e ao método empírico (aspecto importante da fenomenologia), que foram centrais nas críticas sartrianas à psicologia, à psicanálise e à psiquiatria ${ }^{1}$; b) o "espírito sintético" presente na concepção de "compreensão", que foi definidor na questão do método em Sartre; c) a crítica ao atomismo e, em seu lugar, a compreensão do psíquico enquanto totalização, conforme concebe a Psicologia da Gestalt, fundamento da compreensão psicológica sartriana, ainda que acrescida da noção dialética que a completa e supera, colocando-a como processo, em contínuo movimento de totalização; d) a busca de um irredutível psíquico, que em Sartre é entendido como o "projeto de ser" e que define o objetivo maior de sua "psicanálise existencial”; e) os fatos humanos objetivos como: a psique no corpo, a relação intrínseca homem/mundo, o homem objetificado na fala, no trabalho, nas idéias, que serão aspectos aprofundados por Sartre em todas as suas obras, desde seu primeiro ensaio sobre a "intencionalidade em Husserl” até seu O Idiota da Família; f) a vida humana enquanto abertura para o futuro, noção definidora da obra sartriana, por ele aprofundada e colocada em novas dimensões, a partir da noção de projeto; g) o homem enquanto ente cultural, bem como a implicação da história individual na história social, cultural, detalhadamente trabalhadas na Crítica da Razão Dialética; h) enfim, a importância da "biografia" na compreensão do homem e, mais especificamente, a certeza de que toda psicopatologia deve ser esclarecida por uma biografia, aspecto que Sartre desenvolveu em sua proposta metodológica denominada "psicanálise existencial” e em seu Questão de Método, mas que também pôs em prática por meio de seus empreendimentos biográficos (sobre Baudelaire, Genet, Flaubert). Além disso, pode-se refletir sobre o desejo de Jaspers de elaborar uma base ontológica e antropológica para a psiquiatria, exigência sobre a qual Sartre se debruçou seriamente no percurso de seus estudos sobre a psicologia e que o fizeram escrever sua ontologia fenomenológica (O Ser e o Nada) e seu estudo antropológico (Crítica da Razão Dialética).

\section{A Filosofia de Sartre e sua Influência no Movimento Antipsiquiátrico}

A obra sartriana foi escrita ao longo do século XX acompanhando de perto os acontecimentos de seu tempo, não só no campo filosófico, mas também nos campos político e social. Sartre foi um intelectual engajado com sua época, tendo participado ativamente em muitos movimentos políticos e sociais, tais como o maio de 1968 na França. Objetivando expor suas opiniões e idéias, Sartre escreveu romances, peças teatrais, roteiros de cinema, ensaios, manifestos políticos, artigos, além de uma vasta

\footnotetext{
Por exemplo, a crítica que elabora no capítulo "psicanálise existencial” de O Ser e o Nada, onde diz que a psiquiatria se satisfaz ao encontrar as estruturas gerais dos delírios e não se preocupa em compreender o conteúdo individual e concreto das psicoses (Sartre, 1943, p. 646).
} 
e complexa obra técnica-filosófica. A psicologia foi uma disciplina de especial interesse para Sartre e que serviu de fio condutor para suas pesquisas.

Desta forma, considerando o trânsito de Sartre no campo da psicologia crítica, não fica difícil deduzir seu envolvimento com o movimento antipsiquiátrico. Em artigo recente acerca da antipsiquiatria, Christian Delacampagne (2004) inicia seu texto afirmando que a via de Sartre à antipsiquiatria foi direta, ou seja, os subsídios filosóficos fornecidos por ele serviram de base ao questionamento realizado em torno dos pressupostos da psiquiatria clássica. E o próprio Sartre, no prefácio da obra escrita por Laing e Cooper - considerados autores fundadores do movimento antipsiquiátrico, que problematizaram a questão antropológica e epistemológica da psiquiatria - declarou:

Também eu julgo que não se pode compreender as perturbações psíquicas do exterior, a partir de um determinismo positivista, nem reconstruí-las graças a uma combinação de conceitos que permanecem externos à doença. Creio também que não se pode estudar ou curar uma neurose sem o respeito original à pessoa do paciente [...] julgo a 'doença mental' como uma saída que o organismo livre, em sua unidade total, inventa para poder viver uma situação insuportável. [...] e estou convicto de que seus esforços [os de Laing e Cooper] contribuem para acelerar a aproximação do tempo em que a psiquiatria será, finalmente, humana (Sartre citado por Laing \& Cooper, 1982, p. 7)

Ainda que, como assinala Delacampgne (1990), Laing e Cooper fossem, em 1963, ilustres desconhecidos, a corrente antipsiquiátrica britânica não estivesse senão em seu início e ninguém, naquele momento, pudesse prever o impacto que eles acabariam por ter na Europa a partir dos anos 70, Sartre viu em seus trabalhos uma promessa de superação dos impasses em que se encontravam as ciências do homem e, mais especificamente, a psiquiatria e psicanálise. Estava ciente, também, das contribuições que sua obra poderia fornecer a esse movimento crítico que pretendia construir novos modelos clínicos, além de uma nova perspectiva político-social

Em uma entrevista concedida à Charlesworth (1980), Laing falou sobre o "background" teórico que Sartre lhe forneceu para seu trabalho com famílias "esquizofrenizantes”. Explicou que, particularmente na Crítica da Razão Dialética, Sartre desenvolveu conceitos chaves para a compreensão dos fenômenos que investigava nas famílias e nos processos de loucura. A idéia de totalização, de serialização, de constituição dos grupos, de integração da pessoa com o contexto social em que ela está inserida, a noção de práxis e do homem como agente social, entre outras, foram consideradas por Laing como fundamentais para se compreender o sujeito e suas inte- rações sociais, espaço de onde resultaria o adoecimento psíquico.

Na resposta de Sartre à pergunta sobre sua afinidade com os antipsiquiatras, tem-se mais um exemplo da estreita relação teórica que se estabeleceu entre eles:

O que você disse de relevante para mudar a psiquiatria? Penso que o professor Laing estava procurando uma teoria na qual a liberdade pudesse ser colocada em primeiro lugar, dessa forma a doença mental, ou melhor, aquilo que se chama de doença mental, pudesse aparecer como um aspecto da liberdade humana e não como uma doença resultante de um mau funcionamento do cérebro ou de alguma doença física (Sartre citado por Charlesworth, 1980, p. 38).

Sartre também foi um crítico das relações médico-paciente comumente adotadas na psiquiatria e psicanálise clássicas. Estas ocorriam, geralmente, numa posição verticalizada, assunto caro ao movimento antipsiquiátrico que teve na reconstrução da relação terapêutica um dos seus pressupostos básicos. Pode-se verificar esta crítica no conhecido episódio O Homem ao Gravador. Nesta situação, o paciente de um psicanalista gravou uma sessão psicoterapêutica, realizando uma inversão de papéis, onde o analista passou para o lugar de analisando. O paciente questionou a capacidade analítica do terapeuta e o acusou de ter fracassado em sua proposição de cura. Sartre defendeu a sua publicação em Les Temps Modernes, como uma forma de provocar reflexões sobre a irrupção do sujeito no consultório analítico. Além disso, poder-seia pensar sobre os parâmetros da relação analista-analisando e o enquadramento do setting terapêutico (Sartre, 1972). Sartre afirmou que o paciente A. encontraria interlocutores valiosos nos antipsiquiatras da Inglaterra e da Itália, pois estes pretendiam estabelecer entre eles e seus clientes um "compromisso de reciprocidade"; justamente o que faltou ao analista de A., dificultando sua cura, como ele mesmo denuncia com muita propriedade. E acrescentou, ainda, que "esta história, que muitos acharão engraçada, é a tragédia da reciprocidade impossível" (Sartre, 1972, p. 333).

Sartre serviu de mediação intelectual para outros tantos psiquiatras que questionavam a sua disciplina e antipsiquiatras. Um dos mais importantes foi Basaglia, com sua exigência de desinstitucionalização, ou seja, de desconstrução da racionalidade acerca da loucura, pois esta é base para a construção de novos modos de atenção em franca ruptura com a lógica manicomial e a possibilidade de construção de uma clínica ampliada, que nada mais é do que uma clínica do sujeito (Campos, 2007). Basaglia necessitou, nesta direção, trabalhar "a dialética alienação/libertação, ou seja, sobre as maneiras de se produzir Sujeitos com altos coeficientes de autonomia e de iniciativa em situações em que a maioria dos determinantes estaria voltados para a produção da submissão" (Campos, 
2007, p. 52). E acrescenta: "neste ponto, Basaglia viu-se obrigado a apoiar-se em Sartre”, pois o existencialista vai exatamente valorizar o sujeito em uma perspectiva humanista e materialista, ao mesmo tempo. Campos (2007, p. 53) ainda afirma que a clínica basagliana é bem fenomenológica, pois "sai o objeto ontologizado da medicina - a doença - e entra em seu lugar o doente".

Sartre também influenciou outros psiquiatras fenomenológicos, como é o caso de Van Den Berg (1981), que em seu livro O Paciente Psiquiátrico descreve uma outra forma de compreender os fenômenos ligados à loucura, com muitas passagens sustentadas no existencialismo, e Ernest Keen (1979), que em seu livro Introdução à Psicologia Fenomenológica, também descreve novas formas de compreender os problemas existenciais, com muitas referências a Sartre.

A via de mão dupla que se estabeleceu entre Sartre e o movimento antipsiquiátrico possibilitou ao existencialista vislumbrar, cada vez mais, a concretização de seu desejo de pôr em prática suas concepções sobre o homem e o psíquico. Na entrevista que concedeu a Contat \& Rybalka (Sartre, 1976), Sartre afirmou que seu O Idiota da Família poderia ser considerado uma obra antipsiquiátrica. É que, neste livro, o existencialista inaugurou uma abordagem sobre a neurose, considerada como uma forma de um sujeito solucionar um problema vivido como insuportável.

Explicando os novos rumos de desenvolvimento da temática psicopatológica a partir da fenomenologia e do existencialismo até a antipsiquiatria, Delacampgne (1990, p. 660) afirmou ter sido Sartre a ponte que possibilitou o salto de qualidade:

De Kierkegaard, Freud e Jaspers a Sartre, depois de Sartre a Laing e Cooper, se desenha uma linha de aproximação, infinitamente rica de sugestões, realizando a transformação progressiva da loucura em uma linguagem - linguagem obsedante com suas leis específicas, que o terapeuta não pode decifrar senão nela penetrando, apoiado em uma compreensão global das relações entre o ‘louco’ e seu 'meio', compreensão 'totalizante', mas jamais acabada, que abre ela mesma a via de novas iniciativas terapêuticas.

Dessa forma, o endosso de Sartre ao movimento antipsiquiátrico se deu quando este vislumbrou a construção de uma "ciência finalmente humana". A psicopatologia, da mesma forma como em Jaspers, não deveria ser considerada uma "entidade" que definiria o homem "ad infinitum", mas como um "acontecimento" em seu percurso individual-histórico-social. Tal como Sartre afirmou, falando sobre os antipsiquiatras (Charlesworth, 1980), que eles tomam o homem como ele é, não como um homem doente versus um homem sadio. Sendo assim, é o homem que possibilita compreender o ser da doença, e não a doença que define o ser do homem. Em síntese, conclui-se que a articulação entre teoria e práxis, central na reflexão sartriana, esteve sempre presente nas preocupações antipsiquiátricas, de modo a embasá-la epistemologicamente e metodologicamente.

Cabe perguntar, então: que aspectos teóricos da filosofia sartriana permitiram aos antipsiquiatras desenvolver seus questionamentos? Serão abordados aqui, resumidamente, os principais temas, pois este assunto, certamente, daria uma tese.

\section{Contribuições da Psicologia Existencialista para Repensar a Psiquiatria}

Em primeiro lugar, Sartre realizou mudanças ao nível ontológico, começando pela radical distinção entre a consciência e o ego (ou personalidade). A consciência em Sartre é entendida como um componente indescartável da realidade, o pólo da subjetividade, definida pela intencionalidade, segundo nos ensina Husserl. Isso quer dizer que a consciência é pura relação às coisas, pura transparência, é o nada que se insere na realidade constituindo o mundo (Sartre, 1966). Isso implica que a consciência é vazia, não tem conteúdo, embora seja através dela que a presença do sujeito se insira na realidade, transformando-a em realidade humana. A consciência é, portanto, a dimensão da subjetividade.

O ego (ou personalidade), em contrapartida, é a dimensão do sujeito ou a unificação do corpo/consciência em direção a um fim - o projeto. Assim, o ego é a subjetividade objetivada, ou seja, a totalização das ações de um sujeito em meio ao mundo e aos outros. O ego, segundo esta tese, não está na consciência, "está fora, no mundo; é um ser do mundo, como o ego do outro" (Sartre, 2003, p. 93). Ora, isso significa que o ego se constitui no mundo, na relação com as infinitas consciências que um sujeito põe ao longo de sua vida, sendo que este processo vai se totalizando, pouco a pouco, e também se destotalizando, para, logo mais, retotalizar-se e assim reiniciar a dialética. Sim, pois "a subjetividade não é tudo ou nada, mas representa um momento do processo objetivo (o da interiorização da exterioridade) e esse movimento eliminase incessantemente para renascer incessantemente como novo" (Sartre, 2002, p. 38-39).

Critica, com isso, a noção de ego, por exemplo, como aparece na psicanálise freudiana, considerada parte de uma "estrutura mental”, porção aparente, manifesta, determinada por sua dimensão latente, inconsciente. Tal noção encontra-se dentro da lógica cartesiana, quer dizer, parte de uma concepção do psíquico enquanto substância interna, por mais que em Freud essa substância não seja pensante como em Descartes, mas pensada, pois que é determinada por um saber que não se sabe (o inconsciente). Em Descartes, o eu - que sempre é um eu pensante - não é sujeito, no sentido de ser concreto, psicofísico, mas é uma substância que se pensa a si própria, que não precisa 
de tempo, de espaço, nem de corpo para ser (Descartes, 1987). Dessa forma, em Descartes tudo é racional, toda a realidade é definida pelos pensamentos, e o desprezo pelas sensações, pelo corpo, pelo concreto é completo. Quem não segue as normas está, portanto, na desrazão, já que se deixa dominar pelas instâncias irracionais (o id da psicanálise, com suas pulsões). A maioria das filosofias e psicologias corroboram com essas concepções, inclusive postulando que encontraremos nosso verdadeiro eu na medida em que nos libertarmos de toda a materialidade, ou seja, desprendemo-nos do mundo real, material, social e ficamos somente no mundo interior.

Essas noções são totalmente descartadas pela acepção sartriana. O existencialista vai trabalhar com o "cogito pré-reflexivo”, ou seja, com a constatação de que há consciências que são anteriores à reflexão e que têm prioridade ontológica, ou seja, Sartre acaba com a primazia da reflexão, ou com a hipótese da razão ser a instância definidora de toda a realidade vivida, ao estabelecer como ponto de partida o sujeito concreto, totalidade psicofísica, inserido no mundo. Faz balançar, com isso, os alicerces do edifício racionalista. O mentalismo, enquanto desdobramento da filosofia racionalista cartesiana, não tem mais razão de ser. No existencialismo sartriano não há espaço para se pensar em mente, em estrutura mental, nem em eu interior. Diz ele em seu ensaio sobre a intencionalidade em Husserl:

A consciência e o mundo surgem simultaneamente: exterior por essência, o mundo é por essência relativo a ela. (...) Ser - diz Heidegger - é ser-nomundo. Compreenda-se este 'ser em' no sentido de movimento. Ser é estourar no mundo, é partir dum nada de mundo e de consciência para subitamente se-estourar-consciência-no-mundo. Se a consciência tenta recuperar-se, coincidir enfim com ela própria (...), aniquila-se. (...) Hei-nos libertos da 'vida interior'. (...) Por fim, tudo está fora, tudo, até nós próprios: fora, no mundo, entre os outros. Não é em nenhum refúgio que nos descobriremos: é na rua, na cidade, no meio da multidão, coisa entre as coisas, homem entre os homens (Sartre, 1968, p. 31).

É importante distinguir, portanto, o que Sartre chama de plano lógico e plano ontológico. Aquilo que é lógico é relativo às idéias, àquilo que é deduzido reflexivamente (através da razão); em contrapartida, aquilo que é ontológico é referente ao ser, àquilo que é vivido psicofisicamente por um sujeito de "carne e osso" na sua relação concreta com o mundo e com os outros. Esta dimensão ontológica é crucial na produção das complicações e da loucura. A condição essencial, segundo Sartre (1966), para alguém ser "sujeito do seu ser" é ser titular de um projeto. O projeto de ser de um sujeito, como vimos, se constrói a partir de sua ação no mundo mediada pelos outros (em especial, a família), ou seja, ele precisa estar tecido concretamente em uma trama de relações. A psicopatologia seria, então, a inviabilização do projeto de ser do sujeito, onde, de alguma maneira, ficou impedido de alcançar o futuro que deseja. Isso pode ocorrer de várias maneiras: um corte no projeto, uma invalidação no projeto que leva à abdicação do mesmo, a não constituição de um projeto, entre outras formas (Schneider, 2006).

Uma complicação psicológica é acontecimento concreto na vida do sujeito e o leva a experimentar uma contradição de ser. O que é crucial é considerar que tal impasse na constituição da personalidade - ou psicopatologia - formou-se a partir da história de relações do sujeito e é, portanto, para ela que precisamos olhar se quisermos compreender o que está ocorrendo. A ênfase, na filosofia sartriana, é sobre o futuro, pois na medida em que um sujeito é um constante vir-a-ser, seu sofrimento gera uma possível implicação para seu ser no futuro, para aquilo que ele ainda não é, mas que pode vir a ser (Sartre, 1966).

Podemos dizer, então, com Sartre, que um sujeito humano é um ser livre que tem sempre aberto à sua frente um campo de possíveis, um futuro. Ele precisa agir, se fazer: eis o significado da máxima "a existência precede a essência”. E na medida em que sua ação está inserida no mundo, este sujeito será mediado pela materialidade que o cerca e pelas relações sociais e sociológicas (familiares); ou seja, a época histórica em que vive, seu conjunto social e as condições materiais e psicológicas de sua família irá compor sua estrutura de escolha (determinantes antropológicas). Por mais adversas que sejam tais características objetivas, o indivíduo precisa escolher, é livre para escolher ser o que querem que ele seja ou fazer algo daquilo que fizeram dele. A liberdade, em Sartre é, portanto, ontológica; não há como não escolher, visto que não fazer nada é uma escolha. Ser livre é, assim, ter de escolher em cada situação, situação essa que aponta um campo de possibilidades de ser para o sujeito. Aqui é preciso esclarecer que a liberdade não pode ser comparada a uma simples escolha gratuita. Afirma Sartre (1966, p. 530): "isto não significa absolutamente que eu seja livre de me levantar ou me sentar, de entrar ou sair, de fugir ou enfrentar o perigo, se se entende por isso uma pura contingência caprichosa, ilegal, gratuita, incompreensível". Desta forma, liberdade de escolher é muito diferente de liberdade de obter. Sartre cita o exemplo do presidiário que, apesar de não ser livre para sair da prisão quando lhe aprouver, é sempre livre, no entanto, para tentar sua libertação; qualquer que seja sua situação, ele sempre pode projetar sua fuga e descobrir o valor desse projeto. $\mathrm{O}$ sujeito se faz este aquele na medida em que sua ação se faz presente no mundo e, partir dela, ele visa um futuro, algo ainda não alcançado, mas possível (Schneider, 2006).

Uma das características essenciais da liberdade é o compromisso ontológico, significando que, ao escolher, ainda que de forma alienada, sob pressão das circuns- 
tâncias, o sujeito escolhe o ser que ele é e será. A escolha que faz compromete seu ser em um devir. Tem-se que compreender a amplitude da famosa frase do existencialista: "o essencial não é aquilo que se fez do homem, mas sim aquilo que ele fez daquilo que fizeram dele" (Sartre 1952, p. 55). É a expressão do sujeito enquanto liberdade em situação. Estamos cercados de determinações, mas, ainda assim, não somos seres passivos, condicionáveis, pois sempre fazemos algo do que fazem de nós, ainda que seja simplesmente corresponder à expectativa dos outros.

Como vimos, o êxito não importa em absoluto à liberdade. Escutemos o que o filósofo declara na Conferência de Araraquara:

$\mathrm{Eu}$, pessoalmente, falei da liberdade em meus livros de filosofia. Creio mesmo que essa liberdade é a noção capital de nosso mundo. Penso, entretanto, em uma liberdade alienada. Acho que, por ora, o homem é livre para ser alienado. Alienação e liberdade não são, em absoluto, conceitos contraditórios. Muito pelo contrário: se não fosses livre como poderia transformar-te em escravo? Não se escraviza um pedregulho ou uma máquina: só se escraviza e se aliena a um homem que, primeiramente, é livre: não há alienação a não ser de um homem livre. (Sartre 1987, p. 39)

É a partir da recusa de "confundir o homem alienado com uma coisa” (Laing \& Cooper, 1982, p. 37) ou encerrar um sujeito em um diagnóstico biológico e incapacitante que a antipsiquiatria travou sua luta. Porque, segundo Cooper (1982, p. 19-20), “a ação pessoal, em sua essência, é a possibilidade de 'ultrapassar' todas as determinações", ou ainda, "o homem caracteriza-se acima de tudo pelo ultrapassar de uma situação, por ser capaz de fazer e desfazer o que se fez dele" (Laing \& Cooper, 1982, p. 37). Assim, vimos que a personalidade é "a totalização das experiências singulares do sujeito com a materialidade, com o corpo, com o tempo, com os outros, enfim, com o mundo, cujo nexo é o projeto" (Schneider, 2002, p. 291) e, por isso, a complicação psicológica é como um acidente nesta trajetória, estando estreitamente ligada com a história de relações do sujeito. O adoecimento psíquico, portanto, deve ser entendido como parte deste processo, ou seja, há que se admitir uma continuidade entre aquilo que entendemos por normal e patológico.

Um último aspecto relevante a considerar refere-se à dialética dos grupos desenvolvida por Sartre e que fundamenta o peso da família na constituição da personalidade. Somos seres humanos e vivemos em meio a outros seres humanos; isso quer dizer que o significado ou o sentido das coisas é dado pelos próprios sujeitos, sendo revelados no e pelo conjunto social que estes sujeitos compõem. Assim, a realidade humana é delineada, conforme afirma Schneider (2002, p. 222), por laços de reciprocidade, ou seja, "cada um é um meio do outro realizar seu projeto, cada um depende do outro para ser quem quer ser". Um grupo é, portanto, uma empresa em constante movimento de integração (Laing \& Cooper, 1982), de modo que o processo de sociologização é fundamental para que o sujeito se constitua, conferindo, assim, um sentido para seu ser. Essa mediação realizada por aqueles que são próximos - em geral, os familiares - compromete nosso ser, define nosso lugar no mundo, o sentido do nosso projeto. Essas relações de reciprocidade permitem ao sujeito experimentar-se tecido, parte de um grupo de pessoas que "fazem diferença" para sua vida, de modo que não se sinta só. Ora, tal idéia pode parecer banal, mas, na medida em que somos "homens entre os homens" ou seres sociais por excelência, a solidão é o pior sofrimento para um ser humano e, sem dúvida, está na base do enlouquecimento. Considerando, ainda, os inúmeros e diferentes problemas que ocorrem nas relações familiares de nossa época, podemos entender que suas mediações podem tanto viabilizar quanto inviabilizar seus membros. E, somente através de uma ampla investigação compreensiva teremos condições de esclarecer as determinantes de um processo de enlouquecimento e assim revertê-lo.

\section{Considerações Finais}

A Antipsiquiatria, embora considerada um movimento de duração breve, teve e, ainda tem, papel especialmente significativo no campo da saúde mental, pois nos trouxe importantes reflexões sobre o assunto e, através delas, nos convidou a manter a discussão epistemológica. Afirmamos, então, com Delacampagne (2004, p. 32), que suas teses ainda são válidas, pois "ela renovou o campo da reflexão sobre a 'loucura', sobre a oposição entre 'doença' e 'saúde' mental, entre 'normalidade' e 'patologia”.

Sim, pois o objetivo principal deste texto foi o de pensar - através da retomada do movimento antipsiquiátrica - sobre esta ampla e controversa temática que é cada vez mais relevante e requisitada nesta época moderna e que passa não só pelo questionamento da eficácia dos modelos de tratamento existentes, mas fundamentalmente, pelo redimensionamento epistemológico em torno da psicopatologia e da clínica ampliada.

Ora, ainda hoje, e, talvez, sobretudo atualmente, falar em “doença mental” exige que nos perguntemos: tal idéia tem, de fato, alguma utilidade? Qual a sua real origem? Qual o seu efetivo sentido? E, quais as implicações de sua utilização? Fazer uso de tal denominação implica levar em consideração o sentido profundo - compartilhado pela sociedade - do que é ser um "doente mental", pois ele vem sempre "carregado" de significados que trazem conseqüências para todos os envolvidos, em especial para o próprio paciente. Pois seu entendimento se dá dentro de uma lógica fechada, biologicamente determinada, prestando-se, antes de tudo, a encerrar o sujeito 
em um rótulo, a aprisioná-lo em um diagnóstico severo e incapacitante, isentando a sociedade de sua parcela neste processo. Sim, porque se um diagnóstico de "doente mental" diz sobre o modo de ser do sujeito, sobre como age, o que pensa e, principalmente, sobre o que se espera que ele faça, isso é o mesmo encerrá-lo naquilo que se considera que seja sua condição humana. Temos aí uma espécie de condenação, já que o sujeito passa a ter suas ações previstas, como se não pudesse, de fato, alterar esta condição. Isso implica, sobretudo, negar que a personalidade é construída ao longo de um processo sempre em curso e que todo e qualquer sujeito é livre para eleger-se esse ou aquele, mesmo que em circunstâncias terrivelmente adversas e na mais profunda alienação.

Na medida em que o contexto social e sociológico partilha deste significado construído pela psiquiatria, acima descrito, passa a agir frente ao "doente" sob a luz deste diagnóstico, à espreita daqueles comportamentos já esperados, constituindo, assim um jogo de forças centrípetas em torno do sujeito, pressionando-o ainda mais na sua solidão patológica, conseqüentemente, condenando-o cada vez mais ao sofrimento psíquico. O que comumente resulta disso, como sabemos, é a ínfima possibilidade de alteração do quadro, já que o papel destes contextos, em especial, a família, é crucial não só para a compreensão do problema, mas também, para a superação dele. É bem por isso, que a "doença mental" continua a cumprir o papel de mito, como afirma Szasz (1979), pois torna cada vez mais alienante a amarga pílula dos conflitos sociais, dourando-os com uma capa isenta de valores, ao considerá-los como problemas orgânicos ou mentais.

Pensar a saúde mental enquanto saúde coletiva, postulá-la enquanto rede de atenção ao sofrimento psíquico, tomando-a numa perspectiva de saúde integral, são questões cruciais para os necessários avanços na área. Mas estes aspectos têm que estar referendados em novos horizontes epistemológicos, sob pena de reproduzirmos sob novos mecanismos terapêuticos, velhas fórmulas de exclusão social. Desta forma, devemos estar atentos ao desenvolvimento histórico e social da área da saúde mental, pois esta se apresenta cravada por contradições teórico-metodológicas, fruto do embate da tese com a antítese. Daí a necessidade da área da saúde mental estar constantemente colocando-se como questão a problemática das concepções da loucura e das bases epistemológicas da psicopatologia, pois conforme concebemos o sofrimento psíquico, produzimos a realidade de nossas práticas de intervenção.

\section{Referências}

Dartigues, A. (1992). O Que é Fenomenologia. São Paulo: Cortez.

Amarante, P. (2007). Saúde Mental e Atenção Psicossocial. Rio de Janeiro: Fiocruz.
Beauvoir, S. (1960). La Force de l'âge (I e II). Paris: Gallimard.

Campos, G. W. (2007). Saúde Paidéia. Col. Saúde em Debate, $\mathrm{n}^{0}$ 150. 3. ed. São Paulo: Hucitec.

Charlesworth, M. (1980). Sartre, Laing \& Freud. Review of Existential Psychology \& Psychiatry, 17(1), 34-42.

Cooper, D. (1982). Psiquiatria e Antipsiquiatria. São Paulo: Perspectiva.

Costa, J. F. (1983). Ordem Médica e Norma Familiar. Rio de Janeiro: Graal.

Delacampagne, C. (2004). A Contestação antipsiquiátrica. Mental [online], 2, 27-34.

Delacampagne, C. (1990). De l'Existentialisme à l'Antipsychiatrie. Les Temps Modernes, 1 e 2 (531/533), 655-665.

Descartes, R. (1987). Discurso do Método (4. ed.) São Paulo: Nova Cultural.

Jaspers, K. (1979). Psicopatologia Geral. Rio de Janeiro: Atheneu.

Keen, E. (1979). Introdução à Psicologia Fenomenológica. Rio de Janeiro: Interamericana.

Laing, R., \& Cooper, D. (1982). Razão e Violência: uma década da filosofia de Sartre (1950-1960). Petrópolis: Vozes.

Leone, E. (2000). Balanço da produção acadêmica brasileira no campo da saúde mental - 1990/1997. Revista de Ciências Humanas, 121-151.

Pessotti, I. (1994). A Loucura e as Épocas. São Paulo: Edições 34.

Pessotti. (2006). Sobre a teoria da loucura no século XX. Temas em Psicologia, 14, 113-123.

Santos, N. (1994). Do Hospício à Comunidade: Políticas Públicas de Saúde Mental. Florianópolis: Letras Contemporâneas.

Sartre, J-P. (1952). Saint Genet: Comédien et martyr. Paris, Gallimard.

Sartre, J-P. (1966). El Ser y la Nada: ensayo de ontologia y fenomenologia. Buenos Aires: Losada.

Sartre, J-P. (1968). Situações I. Lisboa: Publicações EuropaAmérica.

Sartre, J-P. (1972). Situations IX. Mélanges. Paris: Gallimard.

Sartre, J-P. (1976). Situations X. Politique et Autobiographie. Paris: Gallimard.

Sartre, J-P. (1987). Sartre no Brasil: a Conferência de Araraquara. São Paulo, Paz e Terra/Unesp.

Sartre, J-P. (2002). Crítica da Razão Dialética: precedido por Questão de Método. Rio de Janeiro: DP\&A.

Sartre, J-P.(2003). La Transcendance de L'Ego et autres textes phénoménologiques. Textes introduits et annotés par Vincent de Coorebyter. Paris: J. Vrin. 
Schneider, D. (2002). Novas Perspectivas para a Psicologia Clínica - um estudo a partir da obra "Saint Genet: comédien et martyr" de Jean Paul Sartre. 336p. Tese de Doutorado em Psicologia, Pontifícia Universidade Católica de São Paulo, São Paulo.

Schneider, D. R. (2006). Liberdade e Dinâmica Psicológica em Sartre. Natureza Humana, 8, 283-314.

Szasz, T. (1979). O Mito da Doença Mental. Rio de Janeiro: Zahar.

Van Den Berg, J. (1981). O Paciente Psiquiátrico: esboço de psicopatologia fenomenológica. São Paulo: Mestre Jou.

Daniela Ribeiro Schneider - Psicóloga, Mestre em Educação pela Universidade Federal de Santa Catarina, Doutora em Psicologia Clínica pela Pontifícia Universidade Católica de São Paulo (PUC-SP), Professora do Departamento de Psicologia da Universidade Federal de Santa Catarina. Endereço: Rua Padre Lourenço R. de Andrade, 650 Santo Antônio de Lisboa. Florianópolis. SC. CEP: 88050-400. E-mail: danischneider@cfh.ufsc.br ou danischneiderpsi@uol.com.br

Bianca Sporh - Psicóloga e Mestranda em Filosofia pela Universidade Federal de Santa Catarina. Email: biancaspohr@gmail.com

Recebido em 24.08.09

Aceito em 30.10 .09 